\title{
Standard Sample Preparation for the Analysis of Several Metals on Silicon Wafer
}

\author{
Yoshihiro Mori and Kengo ShImanoe \\ Advanced Materials and Technology Research Laboratories, Nippon Steel Corporation, \\ c/o NSC Electron Corporation, Shimata, Hikari, Yamaguchi 743, Japan
}

Keywords Total reflection X-ray fluorescence spectrometry, standard sample, silicon wafer, contamination, transition metal, SC-1

Since high cleanness of silicon wafer surfaces (below $10^{10}$ atoms $\mathrm{cm}^{-2}$ ) is required in current semiconductor manufacturing, many kinds of sensitive analytical methods are used to evaluate contamination. During the last several years, total-reflection X-ray fluorescence spectrometry (TXRF) ${ }^{1}$ has come into wide use because it is a non-destructive and highly sensitive method (detection limit: $10^{9}-10^{10}$ atoms $\mathrm{cm}^{-2}$ ), and requires no special skills for measurements. In this method, calibration standard samples are required in order to convert the signal intensity into concentration. Because of some special characteristics of TXRF, there are some indispensable conditions for its standard samples: depthprofile reproducibility, uniformity in the surface, and homogeneity in a batch. We have proposed a new preparation method of TXRF standard samples ${ }^{2}$, called IAP, which is short for Immersion in Alkaline Hydrogen Peroxide Solution. In the IAP procedure, one or more silicon wafers are immersed in an intentionally contaminated ammoniac hydrogen peroxide solution. The added metal ions are adsorbed on the surface oxide layer with a thickness of $c a .1 \mathrm{~nm}$. Since this adsorption reaction is governed by chemical equilibria ${ }^{3}$, the obtained wafer shows a suitable property as a TXRF standard sample-reproducible depth profile, good uniformity on the whole surface and good homogeneity in a treatment batch. $^{2}$ In our last paper, we were interested in $\mathrm{Fe}, \mathrm{Ni}$ and $\mathrm{Zn}$ because they are typical contaminants in semiconductor manufacturing. In the present paper, we consider IAP applications to several other metals, such as $\mathrm{Ca}, \mathrm{Co}, \mathrm{Cr}$ and $\mathrm{Mn}$. The stability of IAP wafers prepared for $\mathrm{Ca}, \mathrm{Mn}, \mathrm{Fe}, \mathrm{Co}, \mathrm{Ni}$ and $\mathrm{Zn}$ has also been examined.

\section{Experimental}

\section{Sample preparation}

The wafers examined in this work were silicon single crystals with a polished (100) face; the conductivity at

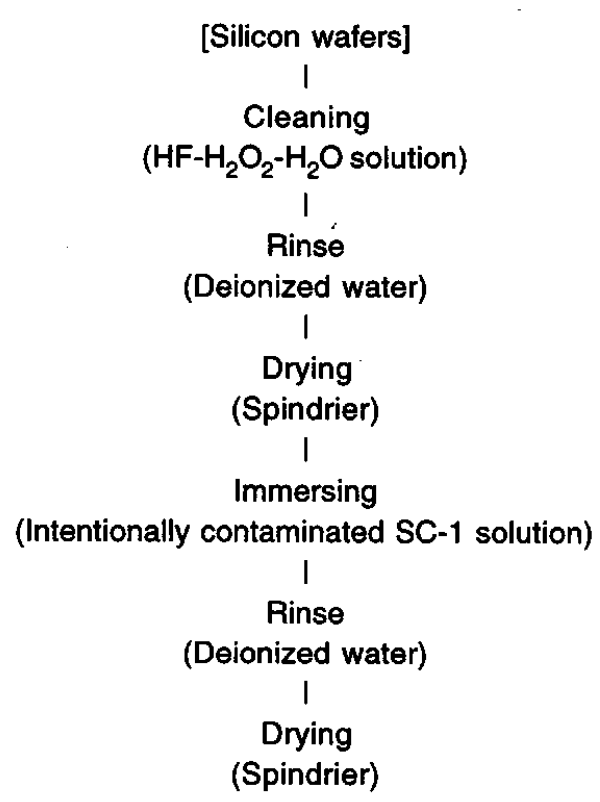

Fig. 1 Sample preparation with the IAP method.

room temperature was $8-12 \Omega \mathrm{cm}$ for both the $\mathrm{n}$ - and $\mathrm{p}$ type. The wafer diameter was $125 \mathrm{~mm}$ and the thickness was $500-600 \mu \mathrm{m}$.

The IAP method is schematically shown in Fig. 1. The wafers were dipped in an $\mathrm{HF}-\mathrm{H}_{2} \mathrm{O}_{2}-\mathrm{H}_{2} \mathrm{O}$ cleaning solution ${ }^{4}$ for $10 \mathrm{~min}$ at $35^{\circ} \mathrm{C}$ in order to remove any initial metal contamination. They were then rinsed in deionized water and dried with a spindrier. They were subsequently immersed in a testing SC-1 solution ${ }^{5}(29 \%$ $\mathrm{NH}_{4} \mathrm{OH}: 31 \% \mathrm{H}_{2} \mathrm{O}_{2}: \mathrm{H}_{2} \mathrm{O}=1: 1: 5$ volume ratio) for $10 \mathrm{~min}$ at $80^{\circ} \mathrm{C}$, rinsed in deionized water and dried with a spindrier. A certain amount of metal standard solution for atomic absorption spectrophotometry (AAS) was added to make the concentration level of the testing SC-1 solution $10^{-9}-10^{-5} \mathrm{~mol} \mathrm{dm}^{-3}$ (ca. $0.1-1000 \mathrm{ppb}$ ).

The chemicals used in this work were of EL grade, 
which contain transition-metal impurities below $0.5 \mathrm{ppb}$, except for AAS standard solutions. The contents of the AAS standard solutions are as follows: $\mathrm{Ca}, \mathrm{CaCO}_{3}$ in $0.1 \mathrm{~mol} \mathrm{dm}^{-3} \mathrm{HCl} ; \mathrm{Cr}, \mathrm{K}_{2} \mathrm{Cr}_{2} \mathrm{O}_{7}$ in $0.01 \mathrm{~mol} \mathrm{dm}^{-3} \mathrm{HNO}_{3}$; $\mathrm{Mn}, \mathrm{Mn}$ in $0.1 \mathrm{~mol} \mathrm{dm}^{-3} \mathrm{HNO}_{3} ; \mathrm{Fe}, \mathrm{Fe}$ in $0.2 \mathrm{~mol} \mathrm{dm}^{-3}$ $\mathrm{HNO}_{3}$; Co, Co in $0.1 \mathrm{~mol} \mathrm{dm}^{-3} \mathrm{HNO}_{3} ; \mathrm{Ni}, \mathrm{Ni}$ in $0.1 \mathrm{~mol} \mathrm{dm}^{-3} \mathrm{HNO}_{3} ; \mathrm{Zn}, \mathrm{Zn}$ in $0.1 \mathrm{~mol} \mathrm{dm}^{-3} \mathrm{HNO}_{3}$. The deionized water contained transition metal impurities below $10 \mathrm{ppt}$.

The IAP wafers were stored in an air-purged wafer cassette made of polypropylene, and the cassette was kept in a clean bench.

All of the above-mentioned processes were carried out in a class- 100 clean room, and wet chemicals were treated inside a clean draft in the room.

\section{$A A S$ and TXRF measurement}

The surface-metal concentration was assigned with a graphite-furnace (GF) AAS using a Perkin-Elmer Z5100 . In the GF-AAS measurement, surface metal contamination on a wafer was collected with $5 \mathrm{ml}$ of mixed acid of $\mathrm{HF}$ and $\mathrm{HNO}_{3}$, injected into the furnace and measured. The surface-metal concentration was measured with a TXRF (Rigaku SYSTEM3726) using monochromatic W-L $\mathrm{L}_{\beta}$ X-ray $(9.67 \mathrm{keV})$ excitation. The applied voltage and current were set at $30 \mathrm{kV}$ and $400 \mathrm{~mA}$, respectively, so as to obtain high sensitivity. In a normal measurement, the glancing angle was 0.10 degree and the integration time was $100-5000 \mathrm{~s}$. However, for an angle scan measurement, the applied current was turned down below $100 \mathrm{~mA}$ so as to avoid saturation of the SSD caused by intense scattered X-rays at high glancing angles. The measured point was the center of the wafer.

All of the measurements were performed in a class1000 clean room, and the AAS pretreatment was carried out inside a clean draft in this room.

\section{Results and Discussion}

\section{Adsorption isotherms}

When TXRF is used for semiconductor analysis, the contamination level is generally in the range between $10^{10}$ and $10^{13}$ atoms $\mathrm{cm}^{-2}$ for transition metals. To achieve a reliable determination at this level, calibration standard samples of this concentration range must be prepared.

In order to clarify the applicable concentration range of the IAP method for several metals, we examined the relationship between the added metal ion concentration and the surface-metal concentration. The results, called "adsorption isotherm", are shown in Fig. 2 for all metals. Chromium was not detected on the surface at all in this experiment. We then added $\mathrm{Cr}$ as $\mathrm{CrCl}_{3}$; the result was the same: it was not detected. According to the $\mathrm{pH}-$ potential diagram of $\mathrm{Cr}^{6}$, the metal easily transforms stable $\mathrm{Cr}(\mathrm{VI})$. Since the adsorption species of transition metals are the dissolved hydroxide complexes ${ }^{3}$, it is considered that the hexavalent chromium, which never

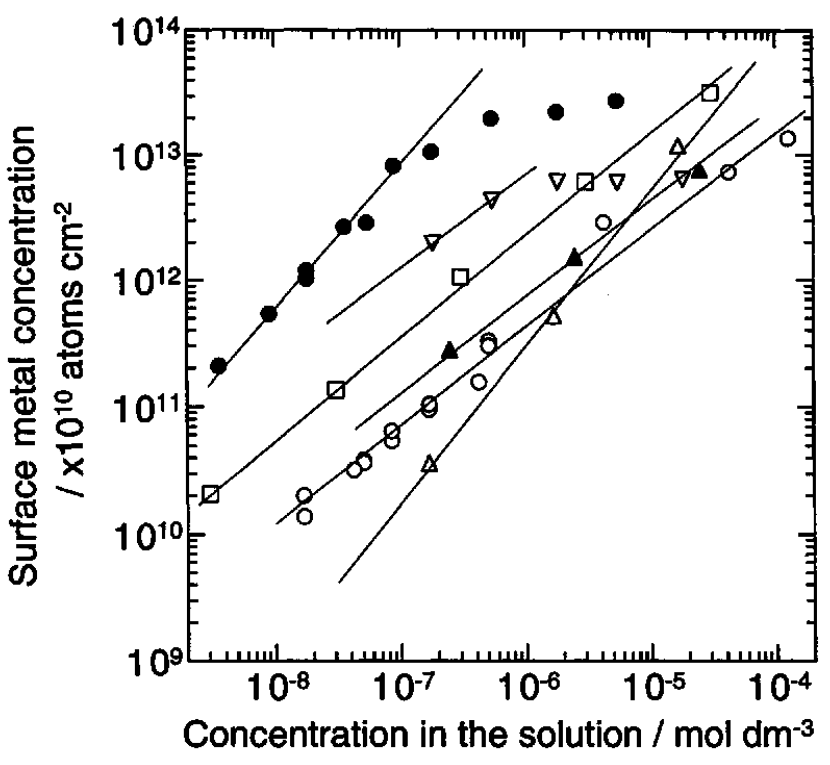

Fig. 2 Adsorption isotherms of calcium $(\boldsymbol{\Lambda})$, manganese $(\nabla)$, iron $(\circlearrowleft)$, cobalt $(\Delta)$, nickel $(O)$ and zinc $(\square)$ on silicon wafer in $\mathrm{SC}-1$ solution.

forms hydroxides ${ }^{6}$, is hard to be adsorbed. Except for $\mathrm{Cr}$, the surface-metal concentration increases monotonically along with the solution concentration in most regions. The linearity means that a chemical reaction governs the metal-ion adsorption, and that the reaction attains an adsorption equilibria. The applicable concentration range for $\mathrm{Ca}$ is at least between $2 \times 10^{11}$ atoms $\mathrm{cm}^{-2}$ and $8 \times 10^{12}$ atoms $\mathrm{cm}^{-2}$; it can be extended to a higher and lower region by controlling the metal concentration in the solution. As for $\mathrm{Co}$, the range is at least between $3 \times 10^{10}$ atoms cm $\mathrm{cm}^{-2}$ and $1 \times 10^{13}$ atoms cm $\mathrm{cm}^{-2}$. Since the surface $\mathrm{Mn}$ concentration shows a saturant tendency, its higher limit is $6 \times 10^{12}$ atoms $\mathrm{cm}^{-2}$. Although the lower limit of $\mathrm{Mn}$ seems to be $2 \times 10^{12}$ atoms $\mathrm{cm}^{-2}$ from Fig. 1, it can be lowered because a monotonic decrease of surface $\mathrm{Mn}$ along with the added concentration is analogically expected. The lower limit may at least achieve $10^{9}-10^{10}$ atoms $\mathrm{cm}^{-2}$, which is the detection limit of TXRF.

Although the accuracy of the adsorption isotherms was not examined minutely in this study, the deviation of the $y$-axis is expected not to exceed $20 \%$ from our previous study. ${ }^{7}$ On the whole, IAP can be applied to most transition metals.

\section{Depth profile}

The depth distribution of the objective element on a standard sample is an essential factor for the determination with TXRF. ${ }^{2}$ We have examined the depth distributions of each of the metals on the IAP wafers by measuring the angle scan profiles.

Figure 3 shows the angle scan profiles of each of the metals examined in this present work. The measurements were carried out just after the production. The 


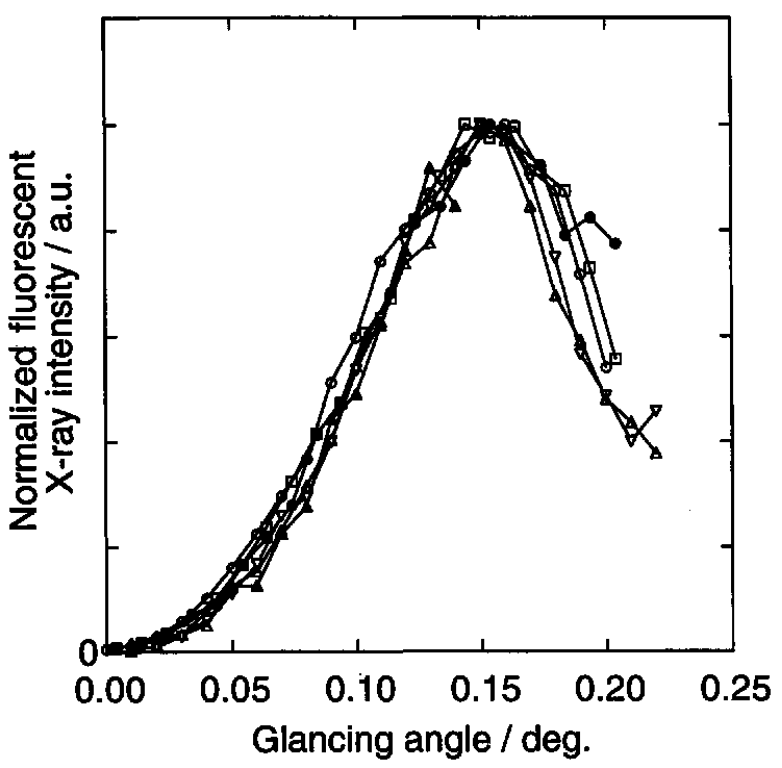

Fig. 3 Angle scan profiles for some IAP wafers just after production $\left(\Delta\right.$, calcium $7.5 \times 10^{12}$ atoms $\mathrm{cm}^{-2} ; \nabla$, manganese $6.4 \times 10^{12}$ atoms $\mathrm{cm}^{-2} ; \ominus$, iron $4.0 \times 10^{12}$ atoms $\mathrm{cm}^{-2} ; \triangle$, cobalt $1.2 \times 10^{13}$ atoms cm${ }^{-2} ; O$, nickel $6.2 \times 10^{12}$ atoms $\mathrm{cm}^{-2} ; \square$, zinc $2.4 \times 10^{13}$ atoms $\mathrm{cm}^{-2}$ ).

fluorescent X-ray intensity is normalized with the maximum value for a comparison of the profiles. They agreed well with each other. This indicates that the IAP method offers the same depth distribution, not only across the samples ${ }^{2}$, but also across the elements.

The reproducibility of the depth distribution originates in the nature of the IAP method itself. It was reported that metal ions which form stable soluble hydroxides, $\mathrm{M}(\mathrm{OH})_{x}$, are adsorbed on the surface $\mathrm{SiO}_{2}$ film of a silicon wafer in an alkaline hydrogen peroxide solution. ${ }^{3}$ Since the adsorption reaction is common to the metals examined here ( $\mathrm{Ca}, \mathrm{Mn}, \mathrm{Fe}, \mathrm{Co}, \mathrm{Ni}$ and $\mathrm{Zn}$ ), the obtained samples show the same quality in depth distribution.

\section{Stability}

In the present work, we examined the long-term stability of IAP wafers, because a standard sample is generally used for some months or longer.

We measured the shift in angle scan profiles of the samples prepared for $\mathrm{Ca}, \mathrm{Mn}, \mathrm{Fe}, \mathrm{Co}, \mathrm{Ni}$ and $\mathrm{Zn}$. Figure 4 shows the profiles measured after more than five months from the production. The consistency of the profiles across the elements, which was observed just after the production (Fig. 3), did not change within this period. It is considered that the long time stability originates due to stable metal-O-Si bonds in the oxide layer formed during the treatment in $\mathrm{SC}-1$ solution.

The IAP method offers standard samples of many metals. The applicable metals are $\mathrm{Ca}, \mathrm{Mn}, \mathrm{Fe}, \mathrm{Co}, \mathrm{Ni}$

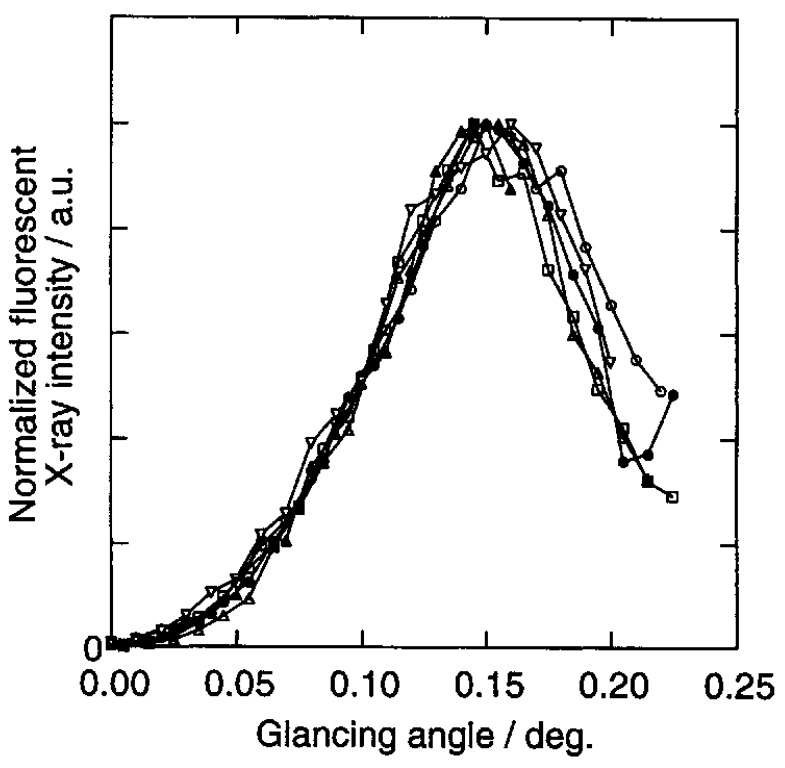

Fig. 4 Angle scan profiles for some IAP wafers after five months from the production (symbols are the same as Fig. 3).

and $\mathrm{Zn}$. Their depth distributions are the same as each other, and are consistent for a long time.

We would like to thank M. Inamitsu, S. Kawai, H. Arigane, M. Yoshitomi and T. Matsunaga for many helpful discussions and for their cooperation.

\section{References}

1. K. Nishihagi, A. Kawabata, T. Taniguchi and S. Ikeda, Proceedings of the First International Symposium on Cleaning Technology in Semiconductor Device Manufacturing, Hollywood, ECS Proceedings, PV90-9, 1990, p. 243.

2. Y. Mori, K. Shimanoe and T. Sakon, Anal. Sci., 11, 499 (1995).

3. Y. Mori, K. Uemura, K. Shimanoe and T. Sakon, $J$. Electrochem. Soc., 142, 3104 (1995).

4. T. Shimono and M. Tsuji, Extended Abstracts of the 179th Electrochemical Society Meeting, Washington, D.C., ECS Proceedings, PV91-1, 1991, p. 278.

5. W. Kern and D. A. Poutinen, RCA Rev., 31, 207 (1970).

6. M. Pourbaix, "Atlas of Electrochemical Equilibria in Aqueous Solution", Section 10.1, Pergamon Press, New York, 1966.

7. Y. Mori, K. Kubota, T. Sakon, I. Inamoto, S. Shinoyama, T. Shigematsu, H. Yonezawa, S. Kurosawa and Y. Ishii, Proceedings of the 55th Symposium on Analytical Chemistry, Toyama, June 1994, p. 179.

(Received September 6, 1995) (Accepted November 7, 1995) 